\title{
Virtual Reality Bridging the Gap between Job Skills Required and University Curriculum Competency in South Africa
}

\author{
Gwatiringa Tsitsi* and Adendorff Chris
}

Nelson Mandela University, South Africa

\begin{abstract}
Pervasive technologies such as Virtual Reality are disrupting and transforming the way we work and learn, necessitating the development of new ways of education to allow future employees to flexibly react to the future world of work and meet the demands of such a digitised working environment. By way of futures methodology, the aim of the research was to identify the present forces, trends and drivers of change that impact the future of education and the future of work. The Six Pillars of Futures Studies approach to research by Inayatullah was applied throughout the study. The mapping (environmental scanning) of Virtual Reality technologies as a driver of change was done, highlighting the impact of such technology on tertiary education and on the world of work. The purpose of the environmental scanning was to uncover existing and driving forces that will influence the future of tertiary education and the future of work. The Causal Layer Analysis (CLA) was the primary futures methodology applied in this research. CLA was used to investigate deeper causal issues from various viewpoints in order to formulate scenarios for the future. The study developed four different future scenarios and the most favourable scenario was used to formulate the recommended vision, "Future Vision of Education and Work in South Africa towards 2030" which incorporates a realistic, attainable and desirable future that could foreground the improvement of the skills gap in the South African context. This preferred future envisages an education system that broadens access to opportunities and provides the skills and competences that people need to thrive in a new sustainable economy.
\end{abstract}

Keywords: Virtual Reality, Future of Education, Future workforce, Job Skills Requirements, Fourth Industrial Revolution, Futures Studies.

\section{Introduction}

Various aspects of our lives are constantly changing as a result of the various resources technology provides. Technology continues to change the way we communicate, the way we relax, study, shop, behave and work. Technological innovation is not only altering every part of our daily lives, but it is also altering industries, business models and even education (EY, 2015). With the ever-increasing speed of change being one of the few constants of the world in which we live, it is no surprise that we cannot predict a single future. There are many megatrends that are helping experts define the future and one such trend predicts that the future is digital (EY, 2015). Digital technologies such as Artificial Intelligence (AI) and Virtual Reality (VR) come to mind when we think of the digital transformation of the world.

Forbes (2016) highlighted the significance of VR as a potential game changer for the future. VR has the potential to offer full sensory immersion into different realities; it can give rise to a virtual social network, has the potential to augment the ease of learning complex things, can make seemingly impossible tasks appear effortless and will make technology more easily accessible and widely adapted. This technology is already being used in education and researchers have concluded that VR provides multisensory immersive environments which engage learners and allows them to visualise information (Eslinger, 1993). In mathematics and science subjects, VR has been used to learn elementary algebra and explain abstract spatial data. Winn and Bricken (1992), after using VR in mathematics, concluded that VR has a great potential of making significant improvements in the way learners are taught at school. Haufmann et al. (2000) made use of VR in geometry and 
mathematics, especially in vector analysis and descriptive geometry. The scholars additionally carried out a survey to find out how students rated VR as a tool for learning and all participants indicated VR as an excellent playground for experiments. In chemical engineering courses, Bell and Fogler (1998) claim that VR has been successfully used in the demonstration of molecular mechanisms. Such applications of VR in education provide exciting possibilities of the extent to which VR could be used to enhance learning.

The job landscape has already been disrupted by the Fourth Industrial Revolution (FIR). The way we work and learn is set to be transformed by the FIR, an industrial revolution that is disrupting business models through extreme automation and connectivity (Kakuru, 2016). Technology is evidently the key component of the FIR and the influence and impact of the FIR is quite extensive and all-encompassing. The changes brought on by the FIR indicate that there will be profound change in the employment landscape (World Economic Forum [WEF], 2016). These changes brought on by the FIR will require new and redesigned competences of future employees. In essence, education will have to respond to the changing requirements in the job and work landscape.

Janssen et. al (2016) pose that for educational institutions to prepare for the changes in the work and job landscape, especially at tertiary level, it is crucial for students to have a technological-oriented learning process that also allows them to gain practical experience. In such a context, VR technologies can be used to provide new opportunities for practical experience in tertiary education. Through VR, practical experiences already being offered by universities can be further intensified by a more immersive and engaging learning experience for students.

The expected future trajectory of the job landscape may present challenges, but there are also unique opportunities. By way of the futures methodology, the intention of this research was to systematically make inquiries, create and suggest foreseeable and desirable future visions. This allowed for an optimistic vision of the future of education and jobs in South Africa. Such visions can be used, in the present, to invest in human capital in such a way that the widening skills gap that exists may be closed, while at the same time leveraging the technological advances of tomorrow (WEF, 2017a).

\section{Research Problem Statement}

As foregrounded in the introduction, most radical changes happening in the global world are due to rapid technological developments and this is creating a disparity between what we are doing and what the future requires. These developments have made changes in the future of education and the future of jobs, but the pace of adoption is not fast enough to face all the unprecedented challenges and demands.

Considering that the emerging forms of the new world of work in the FIR has expeditiously become a lived reality for organisations and their employees, it is becoming apparent that the future will require especially highly qualified workers. Corresponding to that, the reshaping of tertiary education, to the changed conditions of work due to FIR is needed, owing to the fact that:

"[t]he current model of pedagogy, which is at the heart of the modern university, is becoming obsolete. It is increasingly failing to meet the needs of a new generation of students who are about to enter the global knowledge economy.” (Tapscott \& Williams, 2010)

The jobs people have and required skills necessary for success are some of the areas most impacted by technological advances such as the FIR and this is particularly concerning for the South African context. The country experienced a $27.6 \%$ rise in unemployment in the first quarter of 2019 and the rate has averaged at a 25.66\% annual increase since the year 2000 (Trading Economics, 2019). Any further job losses are bound to have an impact on economic growth of the country (Davis, 2015). 
As the Global Competitiveness Index 4.0 indicated, it is imperative for multi-stakeholders in a country to embrace the FIR and other digital technologies in order to gain competitive advantage into the future. This can prove to be difficult in a situation where the education is still offering solutions of the third industrial revolution during the FIR (Fadel et. al, 2015). New ways of education are required to allow the future employees to flexibly react to the future world of work and meet the demands of such a digitised working environment (Richert, Behrens \& Jeschke, 2015). While South Africa's global competitiveness ratio may be above average, there is still need for the country to augment the match between labour force skills and the skills required in jobs.

The World Economic Forum's Human Capital Index is used to ascertain the extent to which countries and economies, through skills development and education, optimise their human capital potential. The 2017 report found that in the sub-Saharan Africa region, only 47\% of the full human capital potential is captured, with southern African countries such as South Africa being among the more successful ones (WEF, 2017a). However, the report notes that despite the higher rates of success, South Africa, for example, rates below the regional average when it comes to the quality of education and the deployment of the workforce. This indicates a mismatch between skilled labour demand and supply.

After 1994, South Africa introduced institutions such as the Sector Education and Training Authorities (SETAs) to plan for skills development in the country and bridge the gap between education and work. However, the interventions facilitated by the SETAs have failed, to a considerable extent, to meet the need for quality skills development (Department of Higher Education and Training [DHET], 2013). The White Paper for Post-School Education and Training has pointed out skills planning, inadequate research capacity, lack of planning expertise and lack of expertise in industry and labour markets as some of the key challenges that have impacted the efforts made by the SETAs (DHET, 2013). South Africa, as a result, continues to find itself in a situation where there is a widening gap between education and work, and this has a negative influence on overall economic growth.

Universities have long been powerful drivers of economic development and most universities in South Africa are actively involved in graduate recruitment programmes that attempt to bridge the skills gap in the country. However, if the unemployment rates are anything to go by, these efforts are inadequate. The South African Graduate Employers Association Candidate Insights Survey of 2018 reported that while an excess of 1500 applications are received for graduate programmes, most of them fail to secure job offers as employers still note a huge shortage of candidates who have the right skills and education to match the job requirements. This results in a mere $7 \%$ average of graduates being employed after graduating university (South African Graduate Employers Association [SAGEA], 2018). Such efforts remain a far cry from effectively reducing the skills gap in South Africa, seeing as there are more than 203078 graduates who leave universities each year (Statistics South Africa, 2016). VR is a technology that could have a positive impact on the current gap between education and work. South Africa could do well if it understood the possibilities that this technology could offer.

It is increasingly evident that the challenge of skills and work mismatch is only just one of the myriads of problems with which future employees are faced. The rapid changes in the world are bringing with them uncertainty in many aspects of life. To navigate through such an era of social, economic and environmental uncertainty, it is important to find solutions for the future. By proposing 'possible futures/alternatives', there is a chance of influencing the future and changing it through decisions and actions (Gonzalez, 2013).

\section{Literature Review}

\section{VR as a Driver of Change}

VR has, over the recent years, prepared to become mainstream. It is currently associated with the use of headsets, but the future of reality will most likely be different as VR has the potential to transform the way 
people see and learn the world. In the future, VR will be much more physical, involving more than headsets and game controllers. Experts are expecting VR to be more sensory-oriented in the future (The Tech Advocate, 2018). Regardless of the aim to use VR, the possibilities of how this technology can be used are endless as VR is advancing almost daily. Over recent years, VR has become a reality for most individuals, businesses and sectors across the world. Put quite simply, VR can take people to new places. This is not only interesting for the entertainment industry - where VR is currently being most used - but it will be beneficial in education too. Virtual field trips and travelling back in time for history lessons are some of the education possibilities brought on by VR (The Tech Advocate, 2018).

With such possibilities, it is not far-fetched to imagine VR taking learners into a virtual workplace to develop their skills and gain work experience. According to Gadelha (2018), VR has the capability to revolutionise education as learners are immersed in their learning more than any other available tool. By blocking out distractions in the classroom, VR has the potential to create a deeper connection with learning material for the students. The 21st century learner is used to technology in their daily lives and they mainly use it for communication and entertainment purposes. To leverage technologies such as VR in the process of learning, it will need to be engaging, meaningful and navigable for students to retain what they learn.

\section{The Changing World of Work \& The Future of Education}

The WEF a yearly Future of Jobs Report which outlines the likely changes in the world of work, such as the types of employment and the skills that will be in demand. In the 2018 report, the WEF highlights that as the FIR unfolds, businesses are seeking to leverage new technologies and seek workers with the right type of skills to enable them to proactively harness the transformative potential of the FIR (WEF, 2018).

As technology continues to drive convergence in almost every industry, there is an opportunity for tertiary education institutions to blur the industry boundaries. According to EY (2018), technology offers universities an opportunity to collaborate with businesses, especially on areas of curriculum design, research and innovation, together with work placements. By working more closely with the industries, the universities of the future can develop curricula that will closely mirror the requirements of the professional work world (EY, 2018).

As it remains a key sector for preparing for the future, the education sector must be transformed to meet and stay in tune with the changes happening in the world. It has been suggested by the WEF that one means in which transformation of the education ecosystem can take place is through creation of curricula that promotes exposure to the world of work, with a long-term intent of professionalising the future workplace. Early exposure to the workplace can be done through mentoring, internships, site visits and access to employer networks as well as leveraging technology to help learners of today to envision the work environment and gain relevant competencies which contribute towards their readiness for work (WEF, 2017b). This is where technologies such as VR can come into play, where students can be exposed to the workplace in a simulated world where they perform the tasks that they would, if they had an employment opportunity. Early workplace exposure can facilitate easier transitions from university to the world of work for graduates.

\section{Conceptual Framework}

The conceptual framework used in this study was based on the Six Pillars of Futures Studies which are proposed by Inayatullah $(2008 ; 2013)$. The conceptual framework, which is presented in Figure 1, confers the proposed techniques and methodology that will be used to turn the extent of understanding into suitably aligned recommendations that can be implemented in South Africa to close the skills gap. 


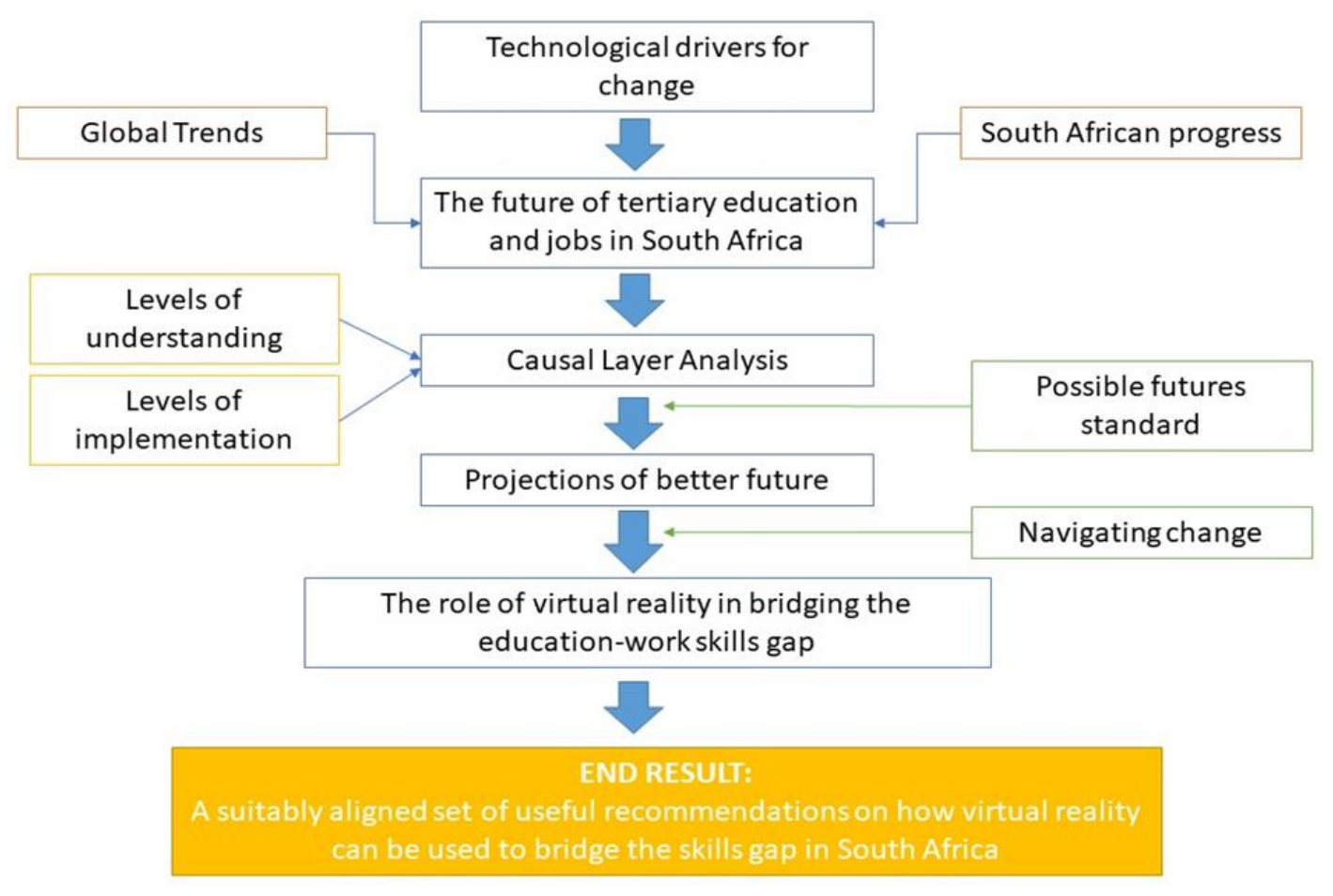

\section{Methodology}

According to Inayatullah, (2010), Futures Studies can be defined as the methodological and systematic consideration of possible, probable and preferable futures, including the worldviews and myths which underlie each future. Futures Studies do not precisely predict what will happen before it happens, and it is not monolithic. In fact, futurists recognise that it is not possible to accurately predict the future, it is only different futures that are indeed possible (Dator, 2007; Kreibich et al., 2011). As a Futures Studies research, this study's aim was to develop different possible future scenarios that can be used to bridge the gap between education qualifications and skills requirement for jobs in South Africa. Öborn et al. (2011) suggest that both qualitative and quantitative factors should be included in the development of possible combinations of futures that can help address the widening gap relating to tertiary education and the job landscape. As such, while largely guided by the Six Pillars of Futures Studies, this study is also located within the mixed methods paradigm. When using a mixedmethod approach to research, both theoretical frameworks and philosophical assumptions are incorporated.

Creswell (1994) outlines a qualitative study as an inquiry process, a process that involves understanding a human or social problem which is based on building either a complex or holistic picture, formed with words and conducted in a natural setting. The qualitative research paradigm is used to explore, explain and understand contexts and environments that surround a research variable. On the other hand, quantitative research uses quantification in arranging the knowledge to refine precision in the narrative of parameters as well as the connections found between them. The qualitative and quantitative elements of the study come through in the application of the Six Pillars of Futures Studies approach to research. These pillars, as indicated by Inayatullah (2008) are mapping, anticipation, timing, deepening, creating alternatives and transforming. The mapping (environmental scanning) of VR technologies as a driver of change was done, highlighting the impact of such technology on tertiary education and on jobs. This reviewing of relevant literature - an indictive/qualitative approach to research - was performed with the aim of uncovering the existing trends and driving forces that will influence the future of tertiary education and jobs. 
In the second pillar of Futures Studies: anticipation, all the data gathered during the environmental scanning in the initial mapping phase may be understood. During the anticipation pillar, there was an analysis of emerging issues and an analysis of drivers was performed to identify critical questions that need to be considered about the future of tertiary education and the future of work in South Africa. The timing pillar involves the searching of grand patterns of change. Key focus is placed on establishing the sources of change. In this study, the identification of the sources of change in the tertiary education sector was guided by three main sources:

- Change that originates from how tertiary education providers view the future of education.

- Institutional change, which can be achieved by initiatives from the government and businesses.

- Change that comes from the use of new technologies.

The Causal Layered Analysis (CLA) is located within the fourth pillar of the Futures Studies approach to research. It was the primary futures methodology in the investigation of deeper casual issues in order to formulate scenarios for the future. According to Inayutullah (2008), CLA is a form of a quantitative data analysis technique which espouses a qualitative approach during the gathering and analysis of data in research. The primary concern for CLA is predicting a distinct future by conducting an inquiry into the nature of the past and the present to create alternative futures. There are four levels of deeper critical inquiry: the litany, social causes, discourse/worldview and the myth/metaphor. Moving an inquiry along these different layers of reality guides one to a better understanding of issues to explore alternative futures (Inayatullah, 2008; Conway, 2012). This method is not used to predict the future, but rather to create transformative spaces that allow for the creation of alternative futures.

In the fifth pillar, the creation of alternative futures happens. This pillar has two important methods, namely nuts and bolts, and scenarios. The study made use of scenarios to create alternative futures. These are discussed more in the results section. The last pillar of Futures Studies is transformation. Here, the desired future can flow from scenarios; that is, the future is tapered toward the preferred future and this is done through a process of questioning. Emphasis is placed on revealing win-win solutions, without any compromises or withdrawal. The preferred future selected for this study is also discussed in the results section.

\section{Research Results and Discussion}

\section{Creating Alternatives: Scenario Planning}

In line with Inayatullah's (2008) structural guidelines, the formulation of alternative futures occurred in the fifth pillar through the formulation of scenarios to expand on the future of education and future of work in South Africa. The study adopted Peter Schwartz's extensive scenario building model, which places focus on the organisational and proffers specified guidelines with which to plot and develop scenarios. Four variables make up the scenario structure (Inayatullah, 2010), which were dubbed with catching titles about 'moving' to accentuate the innate 'stories' of the scenario planning:

- Best case (the most beneficial move for future of education and future of work) "Virtually Going \& Thriving".

- Worst case (the most severe possible outcome) - "Running on Fumes".

- Outlier (a surprising future due to a disruptive emerging issue) - "Sneaky Turn".

- Business as usual (no change, status quo) - "Oh Snap! Never Left". 
The four scenarios designed in this study are a representation of the possible ways in which the future of education and the future of work could take, from a South African perspective. The chance for any of the four scenarios happening is high as all four scenarios were informed by a refined understanding of the factors that will influence the world of work and tertiary education, towards the future.

Under the best-case scenario - which influenced the chosen future suggested by the study, it is the year 2030 and the landscape for tertiary education has been restructured to integrate universities with the industry. Universities have fully adopted technology, unbundled the traditional degree programmes and have moved to individual courses, with priority on training and employability outcomes as humans find ways for machines to work for them without replacing them.

The scenario offers a future where education has leapfrogged from Education 2.0 to Education 4.0 as AI, IoT, robotics, VR and AR have been applied to education. Machines, alongside humans, are managing the learning process and learning is now available from across the world. Students can complete their qualifications from multiple institutions simultaneous. University curricula have been adjusted to prepare learners to be engaged and responsible citizens who are not only ready for the world of work, but also contributing to the sustainability of the world.

Technological structures have become a source of competitive advantage for universities as has the initiatives or programmes that have been designed to offer immersive practical experience that make students more work ready. A 'work experience' course has been developed - in collaboration with the industries and has been embedded in the curricula at universities. Students can participate in this course to earn work experience. VR immerses students in a virtual workplace (which is customised to their qualification and year of study) where they are required to perform specific tasks that are in line with specific job positions and occupations.

Under the "Virtually Going \& Striving" scenario, we see a future where the workplace has become a creative space, there is a more personalised experience for workers and their customers due to the technological advances. VR has created new occupations and university graduates are easily filling in the new roles being created in the world of work. Those who have long been in the labour force are receiving transformative reskilling and upskilling opportunities while still on the job - even as the job is changing. As VR is being used in training of employees, organisations are redesigning their business models without fear of what will happen to their current employees as they are reassigned and quickly and efficiently trained for their new roles in immersive environments.

\section{The Preferred Future}

The study went on to apply the sixth and final pillar of futures studies as suggested by Inayatullah (2008): the pillar of transforming the present and creating the future. In this pillar, transformation occurs through the development of a distinct preferred future, which dovetails with a preferred scenario. In other words, the desired future stems from scenarios. In this phase of transformation, the future can be narrowed down towards the favoured version through the process of agile experimentation and questioning (Inayatullah, 2005). It is imperative that the preferred future reveals a 'win-win' solution, providing a desired future for all relevant stakeholders.

The desired future of tertiary education and future of work in South Africa is set against a backdrop of technological adoption in the workplace and in education, a collaboration between the public and the private sector, with the aim of developing the country into an excellent hub of leveraging the FIR and other critical technologies to offer skills transformation and close the skills gap that currently exists in South Africa. This would be achieved mainly by a transformation of the tertiary education infrastructure, redesigning it to deliver the skilled labour force that is required by Industry 4.0 and policymakers, business leaders and other 
stakeholders will need to cooperate in the embracing of automation and technology's benefits and deal with the new requirements for education, the techno-driven worker transitions and the transition of skills requirement.

The preferred future, dubbed the "Future Vision of Education and Work in South Africa Towards 2030" underpins the creation of a practical and lasting technological strategy that embraces the FIR and adequately produces relevant human capital for sustainable development of the nation. The future-ready education and work strategy will consist of programmes that undertake to deliver on the following:

- An Education 4.0 system that adequately produces graduates with the skills required for Industry 4.0.

- Learning outcomes that offer immersive learning experiences for learners, developing extensive exposure to work experience that is needed in the FIR workforce.

- Enhancing the quality of education by incorporating technology to offer digital learning, personalised learning and to offer practical experience.

- The collaboration between the industry and the education sector in addressing the skills mismatch.

A successful vision of this preferred future should include systemic thinking, envisioning and critical thinking and mindfulness which promote collaboration and multi-stakeholder involvement in decision-making. In the vision, education remains the key to ensuring a sustainable future. By nurturing the right skills, values and behaviours, education can nudge mankind towards the adoption of sustainable lifestyles. Sustainable education is future oriented, it focuses on the development of competencies that are pivotal for understanding the major challenges faced by societies.

\section{Recommendations and Conclusions}

The bridging of the skills gap in South Africa in developing a preferred future necessitates more than scenario planning. Though scenario planning is an efficient methodology that creates fresh insight and knowledge, it will not be enough in bridging the skills gap. Above all, what is required is the commitment and dedication from all relevant decision makers and stakeholders in embracing technological advancement, the FIR, the obsoleteness of the current education system to effectively change the future through the design of strategies that can realise the "Future Vision of Education and Work in South Africa towards 2030".

The four scenarios presented in this study showed how the role of technology can transform the future of education and the future of work in South Africa towards the future. Tertiary educational institutions could use these scenarios as departure points for making strides towards the Global Sustainable Development Education 2030 targets as well as the attainment of the South African NDP's 2030 plan for the future of education.

The adoption of virtually immersive technologies in developing a preferred future for education and work in South Africa requires fresh insight and knowledge regarding technology in education, digital learning, reskilling and upskilling training in the workplace and how drivers of change are pushing the world towards a range of futures. To achieve skills transformation and bridge the skills gap will require committed and collaborative efforts from all stakeholders who want to see a solution to the current skills mismatch.

An aggressive transformation of the South African education system is needed, with technology permeating in every aspect of our lives today, it would be folly to believe the current models of education are capable of teaching and preparing for the future. As businesses are affected by the quality of human skills available, it is imperative that they collaborate with the tertiary education sector. If VR is to succeed in creating an immersive learning environment where students gain work experience, it is critical that those environments enrich students 
with the exact type of skills the industry needs - it would be futile to not collaborate with the very industry that education provides for.

The "Future Vision of Education and Work in South Africa Towards 2030" means there is an alternative future where a skills mismatch does not exist in South Africa. This preferred future not only attempts to resolve the skills mismatch problem faced today, it also discovers tomorrow's skills-related problems and tries to resolve them. In the process, it will future-proof South African people, furnishing them to succeed in the digital and knowledge economy. The challenge is even greater for decision makers in South Africa as the pivotal backbone of the whole economy - education - is failing dismally in sustaining and preparing South Africa for the future.

\section{References}

Bell, J. T., \& Fogler, H. S. (1998).Virtual Reality In The Chemical Engineering Classroom Paper presented at 1998 Annual Conference, Seattle, Washington. 10.18260/1-2--7523

Creswell, J. W. (1994). Research Design Qualitative and Quantitative Approaches. Thousand Oaks. CA: Sage

Dator, J. (2007). What futures studies is and is not. University of Hawaii Research Center for Futures Studies. Retrieved from: http://www.futures.hawaii.edu.

Davis, N. (2015). 5 ways of understanding the Fourth Industrial Revolution. Retrieved from https://agenda. weforum. org/2015/11/5-ways-of-understanding-the-fourth-industrial-revolution/

DHET. (2013). White paper for Post-School Education and Training. Retrieved from http://www.che.ac.za/sites/default/files/publications/White\%20Paper\%20-\%20final\%20for\%20web.pdf.

Eslinger, C. (1993). Education. Encyclopedia of Virtual Environments. Retrieved from

http://www.hitl.washington.edu/scivw/EVE/I.A.1.Displays.html

EY. (2015). Megatrends 2015: Making Sense of a World in Motion. EY.com. https://doi.org/1001663

frogging.pdf.

EY. (2018). Can the universities of today lead learning for tomorrow? Retrieved from www.ey.com/au/futureuniversity

Fadel, C., Bailik, M. \& Trilling, B. (2015). Four-Dimensional Education. Centre for Curriculum Design. Retrieved from http://curriculumredesign.org/

Forbes. (2016). Five Reasons Why Virtual Reality Is A Game-Changer. Retrieved from https://www.forbes.com/sites/robertadams/2016/03/21/5-reasons-why-virtual-reality-is-a-game-

changer/\#6448735241be

Gadelha, R. (2018). Revolutionizing Education: The promise of virtual reality, Childhood Education, 94:1, 4043, DOI: 10.1080/00094056.2018.1420362

Glenn, J.C., \& Gordon, T.J. (2009). Introduction: Futures Research Methodology. Version 3.0 [CR-ROM]. The Millennium Project.

Gonzalez, F. (2013). Possible Futures and The Future We Want. Retrieved from: https://www.bbvaopenmind.com/en/articles.possible-futures-and-the-future-we-want/amp/

Haufmann, H., Schmalstieg, D. \& Wagner, M. (2000). Construct3D: A Virtual Reality Application for Mathematics and Geometry Education, Education and Information Technologies, 5 (4), 263-276.

Inayatullah, S. (2005). Causal Layered Analysis - Deepening the future. Questioning the Future: Methods and Tools for Organizational and Societal Transformation, (1), 1-22.

Inayatullah, S. (2008). Six pillars: Futures thinking for transforming. Foresight, 10(1): 4-21.

Inayatullah, S. (2010). Futures Studies: Theories and Methods. Futures.

Inayatullah, S. (2013). Futures studies: Theories and methods. In: F.D. Junquera (ed.). There's a future: Visions for a better world (Madrid, BBVA, 2013), 36-66. Retrieved from: http://www.wfsf.org.

Janssen, D., Tummel, C., Richert, A., \& Isenhardt, I. (2016). Virtual Environments in Higher Education Immersion as a Key Construct for Learning 4.0. Retrieved from http://dx.doi.org/10.3991/ijac.v9i2.6000 
Kakuru, C. D. (2016). Fourth Industrial Revolution. Retrieved from https://www.weforum.org/agenda/2016/01/what-the-fourth-industrial-revolution-will-do-for-africa

Öborn, I., Magnusson, U., Bengtsson, J., Vrede, K., Fahlbeck, E., Jensen, E.S., ... Rydhmer, L. (2011). Five scenarios for 2050 - conditions for agriculture and land use. Uppsala, Swedish University of Agriculture and Land Use. Retrieved from: http://www.slu.se/framtidenslantbruk.

Richert, A., Behrens, W., Jeschke, S. (2015). Industry 4.0 Meets Generations X, Y and Z Qualification and Training for Working in New Industrial Age. IPW Regionaltagung.

SAGEA. (2018). News: SAGEA Press Release: The SAGEA Employer Benchmark and Candidate Insights 2018. Retrieved from https://sagea.org.za/newsitem-48.htm

Tapscott, D., Williams, A.D. (2010). Innovating the 21st Century University: It's Time. Educause Review 45 (1), 16-29.

The Tech Advocate. (2018). What is the Future of Virtual Reality? Retrieved from: https://www.thetechedvocate.org/what-is-the-future-of-virtual-reality/

Amsterdam, the Netherlands: Elsevier, 169-193.

Trading Economics. (2019). South Africa Unemployment Rate. Retrieved from https://tradingeconomics.com/south-africa/unemployment-rate

WEF. (2016). The Future of Jobs. Retrieved from http://www3.weforum.org/docs/WEF_Future_of_Jobs.pdf.

WEF. (2017a). Realizing Human Potential in the Fourth Industrial Revolution. Retrieved from http://www3.weforum.org/docs/WEF_EGW_Whitepaper.pdf.

WEF. (2017b). Accelerating Workforce Reskilling for the Fourth Industrial Revolution. Retrieved from http://www3.weforum.org/docs/WEF_EGW_White_Paper_Reskilling.pdf

WEF. (2018). The Global Competitiveness Report 2018. Retrieved from http://www3.weforum.org/docs/GCR2018/05FullReport/TheGlobalCompetitivenessReport2018.pdf.

Winn, W. \& Bricken, W. (1992). Designing Virtual Worlds for Use in Mathematics Education: The Example of Experiential Algebra. Educational Technology, 32(12), 12-19. Retrieved from https://www.learntechlib.org/p/170866/. 